\title{
Kernos
}

Revue internationale et pluridisciplinaire de religion grecque antique

$31 \mid 2018$

Varia

\section{La religion grecque dans les cités à l'époque classique}

Zoé Pitz

\section{(2) OpenEdition}

\section{Journals}

Édition électronique

URL : http://journals.openedition.org/kernos/3021

DOI : 10.4000/kernos.3021

ISSN : 2034-7871

\section{Éditeur}

Centre international d'étude de la religion grecque antique

\section{Édition imprimée}

Date de publication : 1 décembre 2018

Pagination : 343

ISBN : 978-2-87562-055-2

ISSN : 0776-3824

Référence électronique

Zoé Pitz, «La religion grecque dans les cités à l'époque classique », Kernos [En ligne], 31 | 2018, mis en ligne le 01 octobre 2018, consulté le 25 janvier 2021. URL : http://journals.openedition.org/kernos/ 3021 ; DOI : https://doi.org/10.4000/kernos.3021

Ce document a été généré automatiquement le 25 janvier 2021.

Kernos 


\title{
La religion grecque dans les cités à l'époque classique
}

\author{
Zoé Pitz
}

\section{RÉFÉRENCE}

Louise BRUIT ZAIDMAN, Pauline SCHMITT PANTEL, La religion grecque dans les cités à l'époque classique, Paris, Armand Colin, 20175 [1989]. 1 vol. 14,9 × 20,9 cm, 282 p. (Cursus Histoire). ISBN : 978-2-20-061818-6.

L'ouvrage présenté ici est la cinquième édition de La religion grecque dans les cités à l'époque classique, paru pour la première fois en 1989. Ce volume, destiné comme les précédentes éditions à des étudiants en Histoire ancienne, est constitué du texte de la quatrième édition (2007), augmenté d'une postface de 10 pages et d'une bibliographie additionnelle. La postface, qui tient compte des recherches récentes effectuées dans le domaine de la religion grecque, s'articule en six points : "Le sacrifice », "La magie », "Les femmes", "L'économie », «Les mythes dans les cités: les contextes d'énonciation » et "Polythéisme ». S'il est incontestable que la postface permet aux étudiants de saisir les approches contemporaines de la religion grecque ancienne, plusieurs ouvrages fondamentaux auraient toutefois pu enrichir encore la mise au point bibliographique. On citera notamment E. EIDINOW, J. KINDT (éd.), The Oxford Handbook of Ancient Greek Religion, Oxford, 2015 ; G. ЕКROTH, The Sacrificial Rituals of Greek Hero-Cults in the Archaic to the Early Hellenistic Periods, Liège, 2002 (Kernos, Suppl. 12) ; E. LUPU, Greek Sacred Law. A Collection of New Documents (NGSL $\left.{ }^{2}\right) .2^{\text {nd }}$ Edition with a Postscript, Leiden/ Boston, 2009 (Religions in the Graeco-Roman World, 152). Quelques modifications au texte de 2007 auraient également pu être apportées, compte tenu de l'évolution de la recherche, comme par exemple le remplacement du terme "victime » - employé à plusieurs reprises au fil de l'exposé - par l'expression « animal sacrificiel ». L'article de P. Brulé et R. Touzé, «Le hiereion, phusis et psuchè d'un medium », in P. BRULÉ, V. MEHL (éd.), Le sacrifice antique. Vestiges, procédures et stratégies, Rennes, 2008, p.111-138, a en 
effet montré pourquoi le mot "victime » ne convient pas en contexte sacrificiel, et de nombreux autres chercheurs insistent à leur tour sur l'importance d'abandonner cette terminologie trop connotée. Quoi qu'il en soit, cette cinquième édition de La religion grecque dans les cités à l'époque classique demeure un excellent ouvrage pour tous ceux qui souhaitent se familiariser avec cette thématique.

\section{AUTEURS}

\section{ZOÉ PITZ}

F.R.S.-FNRS - Université de Liège 